WellBeing International

WBI Studies Repository

10-2003

\title{
Novel Object Test: Examining Nociception and Fear in the Rainbow Trout
}

Lynne U. Sneddon

Roslin Institute

Victoria A. Braithwaite

University of Edinburgh

Michael J. Gentle

Roslin Institute

Follow this and additional works at: https://www.wellbeingintlstudiesrepository.org/acwp_vsm

Part of the Animal Studies Commons, Comparative Psychology Commons, and the Other Animal Sciences Commons

\section{Recommended Citation}

Sneddon, L. U., Braithwaite, V. A., \& Gentle, M. J. (2003). Novel object test: examining nociception and fear in the rainbow trout. The Journal of Pain, 4(8), 431-440.

This material is brought to you for free and open access by WellBeing International. It has been accepted for inclusion by an authorized administrator of the WBI Studies Repository. For more information, please contact wbisr-info@wellbeingintl.org.

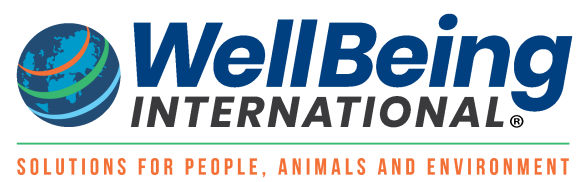




\title{
Novel Object Test: Examining Nociception and Fear in the Rainbow Trout
}

\author{
Lynne U. Sneddon, ${ }^{1}$ Victoria A. Braithwaite, ${ }^{2}$ and Michael J. Gentle ${ }^{1}$ \\ ${ }^{1}$ Roslin Institute \\ ${ }^{2}$ University of Edinburgh
}

\section{KEYWORDS}

Attention, trigeminal pain, nociception, morphine, Oncorhynchus mykiss

\begin{abstract}
This study aimed to assess fear responses to a novel object while experiencing a noxious event to determine whether nociception or fear will dominate attention in a fish in novel object testing paradigm. This experimentally tractable animal model was used to investigate (1) the degree of neophobia to a novel object while experiencing noxious stimulation, (2) the response of the fish after removing the fearcausing event by using a familiar object, and (3) the effects of removing the nociceptive response by morphine administration and examining the response to a novel object. Control animals displayed a classic fear response to the novel objects and spent most of their time moving away from this stimulus, as well as showing an increase in respiration rate when the novel object was presented. In contrast, noxiously stimulated animals spent most of their time in close proximity to the novel object and showed no additional increase in respiration rate to novel object presentation. There was evidence of a slight hypoalgesia in noxiously stimulated animals. The responses to familiar objects demonstrated that by familiarizing the animal with the object, fear was removed from the experiment. Both control and noxiously treated animals responded in similar ways to a novel object by spending the majority of their time in close proximity. Treatment with morphine reduced effects of noxious stimulation and appears to be an effective analgesic. After morphine administration, the acid-injected animals showed a neophobic response to a novel object and this was similar to the response of the control fish, with a similar amount of time spent moving away from the object and an increase in ventilation in response to the novel object. Morphine affected the fear response because both groups approached the novel object more quickly than the non-morphine controls. These results suggest that nociception captures the animal's attention with only a relatively small amount of attention directed at responding to the fear of the novel object.
\end{abstract}

Many studies have examined the interplay of attentional mechanisms on pain thresholds and intensity and on pain-coping strategies. ${ }^{74}$ Results from animal models have suggested that diverting attention toward a novel stimulus reduces pain-related behaviors $\left(\right.$ mice $^{37}$ ) and even inflammation (birds ${ }^{23}$ ). Demonstrating attentional modulation of acute pain in humans is less convincing. The anticipation of receiving a painful stimulus or participating in cognitive tasks in clinical studies has been shown to modify pain responses (eg, reduction of jaw reflex ${ }^{47}$ ), but some studies have reported no change in pain intensity and threshold when attempting to divert attention. ${ }^{41}$ In particular, research on learning ${ }^{42}$ and memory 
tasks $^{25,65}$ such as concentration ${ }^{33}$ or attentiveness ${ }^{15}$ have demonstrated that in humans pain predominates attention and has a negative impact on performance of such tasks. For example, human subjects experiencing pain judged words significantly slower and recalled fewer words in a memory task. ${ }^{43}$ Therefore, pain adversely affects the acquisition and retrieval of information.

Anxiety or fear also has an important role in pain modulation because it has an impact on pain-specific fear and avoidance behavior. ${ }^{2}$ In animal models, exposure to a stressful or potentially fearful stimulation appears to produce a reduction in pain reactivity. ${ }^{38}$ This stress or environmentally induced analgesia is evident in laboratory ${ }^{1,26}$ and ecological studies. ${ }^{31,35,36,44,50,56-58,64}$ The findings of these animal studies have suggested that stress-induced analgesia is advantageous in fearful situations, such as confrontation by a predator, to show no signs of distress and thereby avoid attack. Stress-induced analgesia might therefore be a defensive strategy. ${ }^{38}$ This suggests that fear or anxiety might be a more demanding or higher priority stimulation and might take precedence over pain processing, and as such the intensity of pain might be reduced.

The present study aimed to examine the interplay of fear and nociception and to determine what effects a noxious experience might have on an individual's response to a fearful stimulus. An animal model was used because the study species, a lower vertebrate, the rainbow trout (Oncorhynchus mykiss), is experimentally tractable for this study. The behavioral responses to acute noxious stimulation have been established in this fish, as well as the neurophysiology of the trigeminal nociceptors, which have similar properties to mammalian nociceptors. ${ }^{68-70}$ Relatively little is known about nociception in fish, and so the use of a lower vertebrate might demonstrate evolutionary differences between vertebrate groups. The subjects were subcutaneously injected with acid, and their neophobic responses were investigated and compared with saline-injected animals. Neophobia is a well-established paradigm used to assess fearfulness in a variety of animals (rats, ${ }^{28,29}$ mice, ${ }^{6,20}$ horses, ${ }^{75}$ cats, ${ }^{50}$ birds, ${ }^{67}$ and fish ${ }^{78}$ ) and is defined as the avoidance of an unfamiliar object in a familiar environment. ${ }^{3}$ Responses to novel or unfamiliar objects are not only characterized by behavioral aversion but also by potentially detrimental, aversive physiologic responses. ${ }^{5,26,30,54,76}$ These reactions have been shown to be comparable to threatening situations. ${ }^{8,64}$ Exposure to a fearful situation might cause a fear-induced analgesia with a reduction in the intensity of pain. ${ }^{13}$ This could be interpreted as fear taking priority over pain in attention. However, pain might be a more demanding stimulation, and thus neophobia might be reduced. This study attempted to determine the relationship between fear and nociception to assess whether fear responses to a novel object are affected by being in pain.

The study was designed to investigate 3 responses: (1) responses to a novel object, (2) responses to a familiar object (ie, removing the fear), and (3) responses to a novel object after morphine administration (ie, removing the pain). It was expected that there would be less aversion to a familiar object, and this test acted as a control to demonstrate that the responses to the novel object are phobic. Any change in neophobia when in pain should be ameliorated by an analgesic, morphine, and, therefore, the noxiously stimulated animals should show a similar neophobic response to the control animals. The relationship between pain and fear is probably dynamic and the direction of the influence might vary with the situation, and so this study also examines the question of whether a noxious stimulus attenuates the fear response to a novel stimulus.

\section{Materials and Methods}

Rainbow trout $(\mathrm{n}=30$; mean weight, $64.4 \pm 6.1 \mathrm{~g}$; mean length, $15.7 \pm 0.5 \mathrm{~cm}$ ) were obtained from a commercial fish supplier and kept in individual tanks $(45 \times 25 \times 35 \mathrm{~cm})$. Each tank had a flow through supply of filtered fresh water kept at approximately $14^{\circ} \mathrm{C}$. The experiments were conducted between April and June 2002, and the tanks were kept under ambient light conditions. Each tank had opaque sides for 
visual isolation and was also screened from visual disturbance. The tanks had a constant supply of air bubbled through an air stone connected to an air pump (Mistral Series 4; Interpet, Surrey, UK) via airline tubing. A Series 1 internal filter (Interpet) was also present in each tank to remove debris and uneaten food. The tanks were covered by a Perspex (Lucite International, Lancashire, UK) lid, half of which was covered by opaque polyethylene $(22.5 \times 25 \mathrm{~cm})$ secured to the lid, to provide a covered area for sheltering. In the uncovered area, a white feeding ring (10-cm diameter) was secured to the side of the tank and floated on the surface of the water. The tanks also had transparent tape fixed along the bottom and sides of the tank with a centimeter scale drawn on by a waterproof marker pen. Fish were trained twice daily (AM and PM) on a simple conditioning task in which they had to come to a feeding ring in response to a light cue to receive food. Once a fish had successfully learned this task and performed it for 8 consecutive trials, it was assumed that its behavior was normal or stress free because it could acquire a learning task and it was ingesting food. Stressed fish tend to show anorexia. ${ }^{43}$ Fish were then assigned to the following experimental test groups. Experimental protocols were approved by the Roslin Institute's Ethical Review Board.

\section{Test Group 1: Response to a Novel Object}

\section{Day 1}

Observations were made on each fish twice for 30 minutes (AM and PM) to record normal opercular beat rate (OBR) (gill movements). The fish $(n=10)$ were observed through a small opening in the screening in front of the tank. OBR was recorded 6 times during the 30-minute observation time, and a mean rate per minute was calculated.

\section{Day 2}

Fish were individually anesthetized by using benzocaine $(1.5 \mathrm{~mL}[50 \mathrm{mg} / \mathrm{L}$ ethanol]/L) and were assigned to an Acid group or a Control group. The Acid group were carefully injected with $0.1 \mathrm{~mL}$ of $2 \%$ acetic acid subcutaneously into the upper and lower frontal lip $(n=5)$, and the Control group were injected in a similar fashion with sterile saline $(n=5)$. An injection of $2 \%$ acetic acid has prolonged effects on the fish's behavior and physiology lasting approximately 5 to 6 hours (unpublished observation), whereas a $0.1 \%$ injection only lasts for 3 hours. ${ }^{71}$ Acetic acid was chosen because the protons of the acid stimulate nociceptive nerves in mammals. ${ }^{48}$ The fish were in medium to deep plane anesthesia during this procedure and had lost all reflex activity and muscular control. Trout were placed back into their original tank and allowed 30 minutes to recover from the anesthesia. After 30 minutes the fish's behavior was recorded for 5 minutes. This consisted of the frequency of nociception-related behaviors. These nociceptive behaviors have been described by Sneddon et $\mathrm{al}^{71}$ and are either rocking in which the fish rocks from side to side on the substrate on either pectoral fin or rubbing in which the fish rubs the front lips into the substrate and against the sides of the tank. After this 5-minute observation period, a novel object was slowly lowered into the tank so not to startle the fish and was placed approximately $10 \mathrm{~cm}$ from the head of the fish. The fish's response to this was noted during the following 15 minutes, and the distance that the fish was from object at all times was judged by using the scale bars present at the bottom and up the sides of the tank. Behaviors were also recorded after novel object presentation as well as OBR, which was measured at 1, 5, 10, and 15 minutes after object presentation. Once the object had been present for 15 minutes, it was carefully removed. Novel object presentation was repeated an additional 4 times at hourly intervals, and at each presentation a differently shaped and colored novel object was used. The novel objects were made of Lego (Billund, Denmark) Duplo bricks and were red; yellow; green; blue, or black in color. The novel objects were made up of a combination of bricks that were no longer than $9 \mathrm{~cm}$ in length and $6 \mathrm{~cm}$ in height. This created 5 different novel objects, and these 
were presented in a random order to each of the 5 fish in the Acid group. The Control group had the same order of presentation per fish to make the results comparable between the 2 groups.

\section{Test Group 2: Response to a Familiar Object}

A different set of fish $(n=10)$ in this test group were trained on the conditioning task as described above except that after they had successfully performed the task 4 times, they had 1 of the objects carefully placed into their tank after the AM training trial and removed after the PM training trial. This was done for 4 days before testing so that the fish could become familiar with the object and were exposed to it for approximately 8 hours per day.

\section{Day 1}

Recordings of the normal respiration rate of the fish were made as described for Test Group 1. The AM observation was made without the object being present, whereas the PM observation did have the object present. Therefore, the distance that the fish was from the familiar object could be recorded and compared with the results from day 2.

\section{Day 2}

The fish were divided into the Acid group $(n=5)$ and Control group $(n=5)$. The experiment was conducted as described for day 2 in Test Group 1 except the familiar object was used at each presentation.

\section{Test Group 3: Response to a Novel Object After Morphine Administration}

\section{Day 1}

The experiment was conducted as described for day 1 in Test Group 1 by using a different group of fish $(n=10)$.

\section{Day 2}

The experiment was carried out as described for day 2 in Test Group 1 except that after injection of the acid $(n=5)$ or saline $(n=5)$, morphine sulfate at a dose of $0.3 \mathrm{mg} / \mathrm{g}$ intramuscularly $(30 \mathrm{mg} / 1 \mathrm{~mL}$ sterile saline) was injected intramuscularly $(0.1 \mathrm{~mL} / 10 \mathrm{~g}$ fish weight). This analgesic dose was previously used by Ehrensing et $\mathrm{al}^{19}$ to block the learning of aversive conditioning by using electric shock in goldfish, and this was reversed by using naloxone. Diffusion time for morphine after intramuscular injection is not known in fish, but previous work has shown that it took approximately 10 minutes for intramuscularly injected pancuronium to be effective (unpublished observation). Therefore, the 30-minute recovery period after morphine injection is likely to be sufficient time for the analgesic to have diffused into the blood and body tissues.

\section{Statistical Analyses}

The data were not normally distributed, so nonparametric tests were used throughout. The proportion or percentage of time spent between 0 and $5 \mathrm{~cm}(<5 \mathrm{~cm}) ; 5$ and $10 \mathrm{~cm}(<10 \mathrm{~cm})$; and greater than $10 \mathrm{~cm}$ $(>11 \mathrm{~cm})$ was calculated for each fish in each test group. These distances were chosen because nearer than $5 \mathrm{~cm}$ was closer in proximity to where the object was originally placed and greater than $10 \mathrm{~cm}$ was a direct movement away from the object, whereas between 5 and $10 \mathrm{~cm}$ might indicate no particular movement toward or away from the object. The proportion of time spent at less than $5 \mathrm{~cm}$ and greater than $10 \mathrm{~cm}$ was compared between the Acid and Control groups by using Kruskal-Wallis tests, as was 
the latency to approach the object within each test group and between test groups. Respiration rate was compared for the mean value of day 1 with the mean for day 2 both before and after novel object presentation by using a Kruskal-Wallis test. To determine whether there was a significant change in respiration rate before and after object presentation, Mann-Whitney $U$ test was used to compare the data. Rocking and rubbing were only performed by the Acid group on day 2, so the frequencies of these behaviors were tested before and after novel object presentation by using Mann-Whitney $U$ tests. The influence of individual differences and presentation time differences was also investigated for each parameter by using Kruskal-Wallis tests. The tests were performed within test group to compare Control and Acid groups but also between test groups to understand the differences between neophobia, familiarity, and morphine analgesia. All $P$ values were adjusted for multiple testing where appropriate.

Figure 1. Mean latency ( $+S D$ ) to approach the objects for each of the 3 test groups ( $n=5$ for both Control [shaded bars] and Acid [open bars] groups). Test group 1 had a novel object presented, Test group 2 had a familiar object presented, and Test group 3 had morphine administered before novel object presentation. ${ }^{*} P=.001$; NS, not significant.

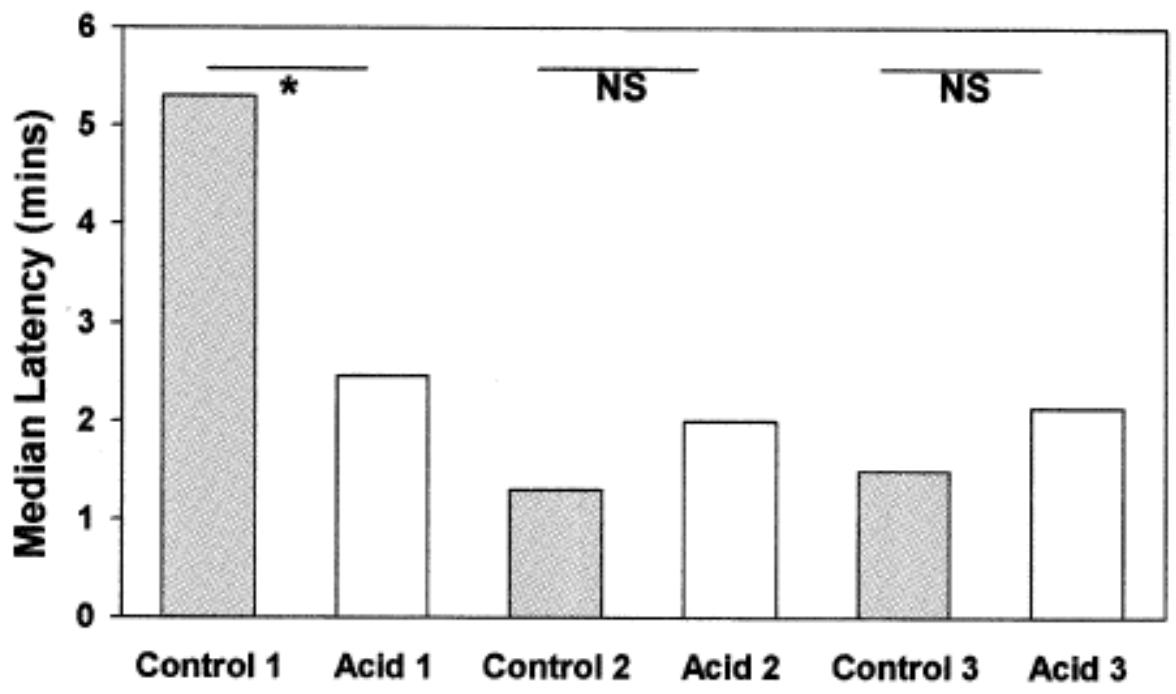

\section{Results}

The data were analyzed to assess individual or presentation time effects on the behavior and respiration rate. There were only presentation time effects on OBR because this declined over time in all treatment and test groups $(H=22.7, d f=14, P=.001)$.

\section{Response to a Novel Object}

\section{Latency to Approach the Object}

The latency to approach the novel object was affected by noxious stimulation and was longer for the Control group (mean, $6.8 \pm$ standard deviation 4.0 seconds) than the Acid group $(3.19 \pm 3.0$ seconds; $\mathrm{H}=$ 12.01, $d f=1, P=.001 ;$ Fig 1$)$.

\section{Time Spent Moving to and Moving Away From the Object}

Noxious stimulation significantly affected the time spent within $5 \mathrm{~cm}$ of the novel object, with the Acid group spending the majority of time in close proximity (Control, $2.15 \% \pm 3.6 \%$; Acid, $31.75 \% \pm 26 \%$; $\mathrm{H}=$ $32.33, d f=1, P<.001 ;$ Fig $2 \mathrm{~A})$. The proportion of time spent moving away from the novel object $(>10 \mathrm{~cm})$ 
was also significantly different between the Acid $(19.62 \% \pm 23 \%)$ and Control groups $(76.93 \pm 25 \% ; \mathrm{H}=$ 28.1; $d f=1, P<.001 ;$ Fig 2B).

Figure 2. (A) The mean (+SD) proportion of time spent within $5 \mathrm{~cm}$ of the object for each of the 3 test groups. (B) The mean (+SD) proportion of time spent at distances greater than $10 \mathrm{~cm}$ of the object for each test group $(n=5$ for both Control [shaded bars] and Acid [open bars] groups). Test group 1 had a novel object presented, Test group 2 had a familiar object presented, and Test group 3 had morphine administered before novel object presentation. ${ }^{* \star} P<.001$; ${ }^{*} P<.05 ; \mathrm{NS}$, not significant.

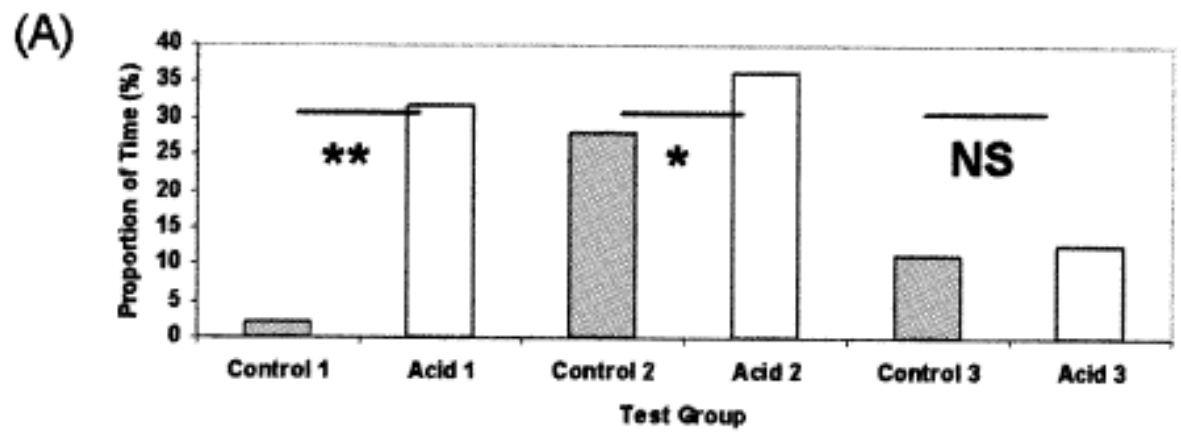

(B)

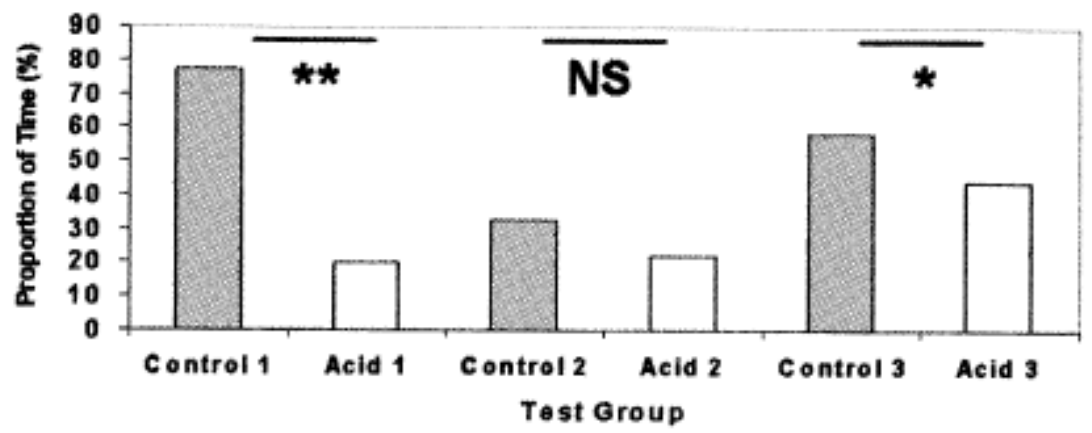

\section{OBR}

OBR was higher on Day 2 when compared with Day 1 rates for both the Control group (Day 1, median 52.6 beats/min; Day 2 before, median 67.2 beats/min; Day 2 after, median 72.0 beats $/ \mathrm{min} ; \mathrm{H}=12.52, d f$ $=2, P=.002$ ) and the Acid group (Day 1, median 55.2 beats $/ \mathrm{min}$; Day 2, before: median 80.0 beats $/ \mathrm{min}$; Day 2 after: 78.0 beats $/ \mathrm{min} ; \mathrm{H}=11.18, d f=2, P=.004)$. OBR significantly increased after novel object presentation only in the Control group (pre-object median, 68 beats/min; post-object median, 74 beats/min; $W=444, P<.001, n=25 ;$ Fig 3B). No such change was recorded in OBR after novel object presentation in the Acid group ( $\mathrm{W}=693.5, P=.280, \mathrm{n}=25$; Fig 3B). Overall OBR was higher in the Acid group (median, 78 beats $/ \mathrm{min}$ ) than in the control group (median, 67 beats $/ \mathrm{min} ; \mathrm{H}=5.40, d f=1, P=.020$ ) on Day 2.

\section{Performance of Nociception-Related Behaviors}

The frequency of rocking declined with presentation time both before $(H=11.16, d f=4, P=.025)$ and after the novel object $(\mathrm{H}=14.8, d f=4, P=.005)$. The frequency of rocking was the same before and after the presentation of the novel object $(\mathrm{W}=30, P=.676, \mathrm{n}=10$; Fig $4 \mathrm{~A})$. 
The frequency of rubbing declined with time and so there was a difference between presentation times, but this was only significant before the novel object presentation (before: $\mathrm{H}=13.99$, $d f=4, P=.007$; after: $\mathrm{H}=8.0, d f=4, P=.092)$. The fish showed a reduction in rubbing after novel object presentation $(\mathrm{W}=742, P=.044 ; \mathrm{n}=15 ;$ Fig $4 \mathrm{~B})$.

Figure 3. Mean (+SD) OBR or respiration rate before and after object presentation. Test group 1 had a novel object presented, Test group 2 had a familiar object presented, and Test group 3 had morphine administered before novel object presentation. ${ }^{\star \star} P<.001 ;{ }^{*} P<.005$; NS (ns), not significant. (Comparison between control and treatment groups under line; comparison between before and after respiration rates on data bars).

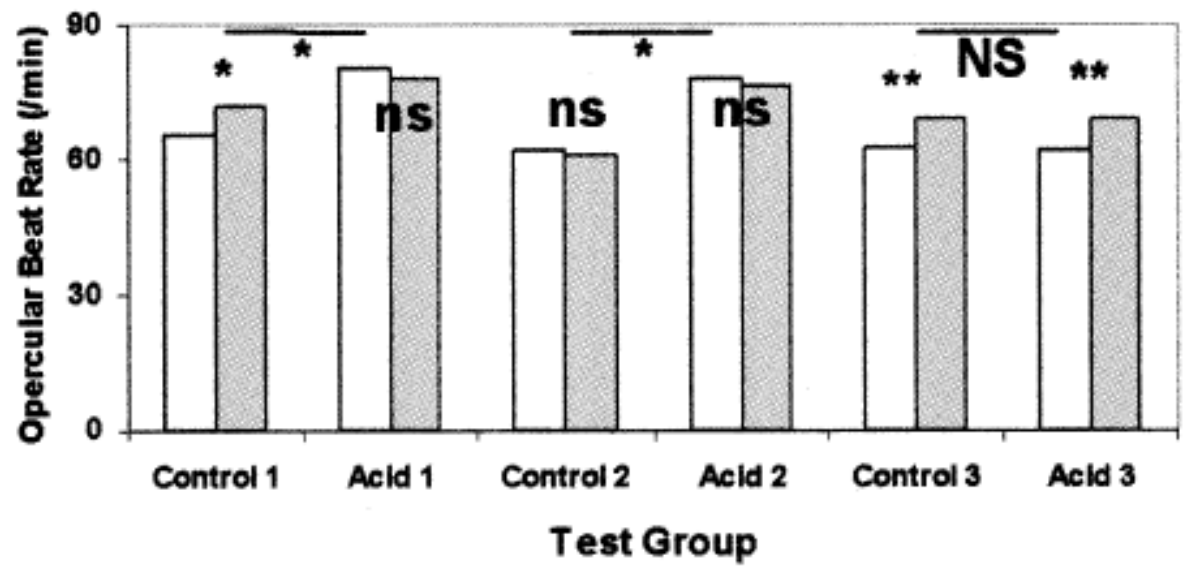

\section{Response to a Familiar Object}

\section{Latency to Approach the Object}

The latency to approach the familiar object was similar for the Control group (mean, $1.6 \pm 1.0$ seconds) and the Acid group (2.27 \pm 1.8 seconds; $\mathrm{H}=0.92, d f=1, P=.336$; Fig 1$)$.

\section{Time Spent Moving to and Moving Away From the Object}

There was no difference in the amount of time spent near the object on Day 1 and at the 5 presentations of the familiar object on Day $2(\mathrm{H}=0.3, d f=5, P=.998)$. Although there was a trend for the Acid group to spend more time within $5 \mathrm{~cm}$ of the familiar object than the Control group (Control, $27.8 \% \pm 22 \%$; Acid, $36.2 \% \pm 17 \% ; \mathrm{H}=5.89, d f=1, P=.015$; Fig 2A). The proportion of time spent moving away from the object $(>10 \mathrm{~cm})$ was not significantly different between the Acid $(32.6 \% \pm 25 \%)$ and Control groups $(22.2 \% \pm 17 \% ; \mathrm{H}=3.2 ; d f=1, P=.073 ;$ Fig $2 \mathrm{~B})$.

\section{OBR}

OBR was much lower on Day 1 (median, 52.0 beats/min) than on Day 2 before (median, 61.6 beats $/ \mathrm{min}$ ) and after (median, 61.6 beats $/ \mathrm{min})$ the presentation of the familiar object in the Control group $(\mathrm{H}=9.71$, $d f=2, P=.008$ ) and the Acid group (Day 1 median, 54.0 beats/min; Day 2 before: median, 78.2 beats/min; Day 2 after: 76.4 beats/min; $\mathrm{H}=10.5, d f=2, P=.005)$. There was no change in OBR after familiar object presentation in the Acid group $(\mathrm{W}=684, P=.372, \mathrm{n}=25)$ or in the Control group $(\mathrm{W}=$ $652, P=.786, \mathrm{n}=25$; Fig 3B). OBR was higher in the Acid group (median, 76 beats $/ \mathrm{min}$ ) than in the Control group (median, 61 beats $/ \mathrm{min} ; \mathrm{H}=5.40, d f=1, P=.020$ ) on Day 2. 
Figure 4. (A) Mean (+SD) performance of rocking before (open bars) and after (shaded bars) object presentation. (B) Mean (+SD) performance of rubbing before and after object presentation. Test group 1 had a novel object presented, Test group 2 had a familiar object presented, and Test group 3 had morphine administered before novel object presentation. ${ }^{*} P<.05$; NS, not significant.
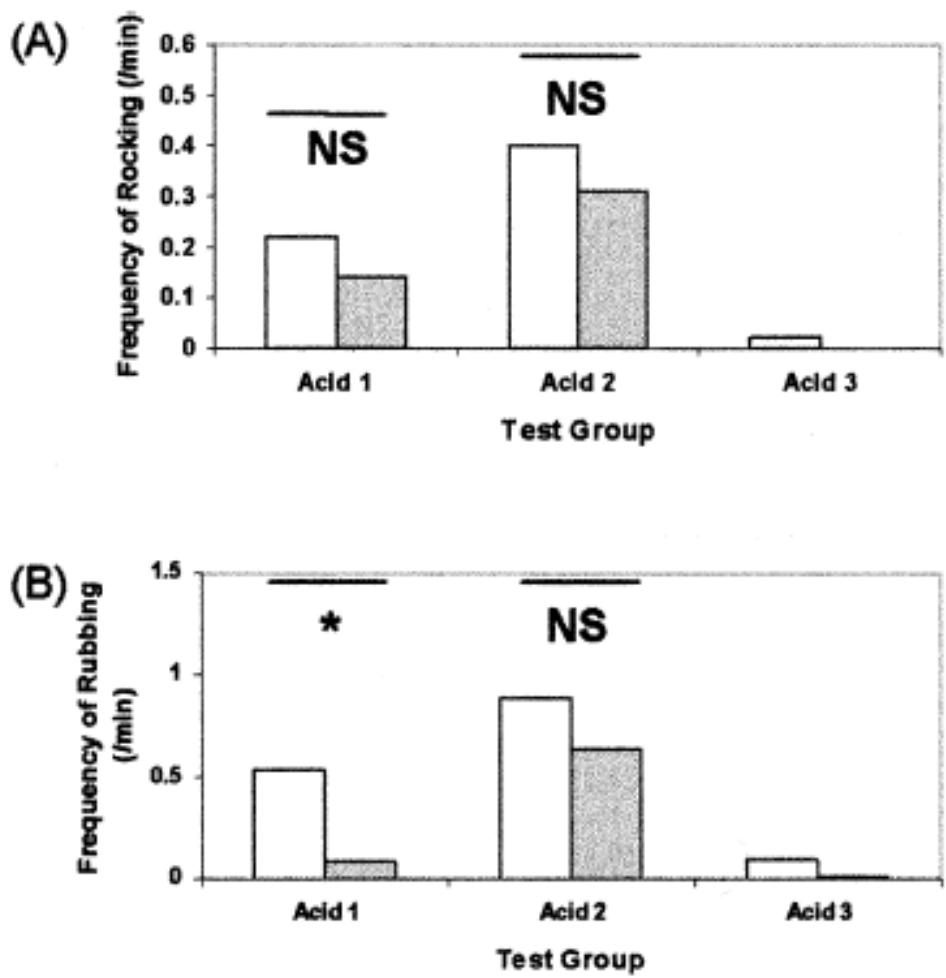

\section{Behaviors}

The frequency of rocking declined with presentation time both before $(\mathrm{H}=19.37, d f=4, P=.001)$ and after the familiar object $(H=19.14, d f=4, P=.001)$. There was no difference in the frequency of rocking before and after the presentation of the object $(\mathrm{W}=643.5, P=.915, \mathrm{n}=10$; Fig $4 \mathrm{~A})$.

The frequency of rocking declined with time and so there was a difference between presentation times, but this was only significant before the novel object presentation (before: $\mathrm{H}=19.2, d f=4, P=.001$; after: $\mathrm{H}=19.5, d f=4, P=.001)$. There was no reduction in rubbing after familiar object presentation $(\mathrm{W}=$ $659.5, P=.652 ; \mathrm{n}=15 ;$ Fig. 4B).

\section{Response to a Novel Object After Morphine Administration}

\section{Latency to Approach the Object}

The latency to approach the novel object was similar for the Control group (mean, $2.42 \pm 2.2$ seconds) and the Acid group (mean, $2.19 \pm 1.3$ seconds; $\mathrm{H}=0.20, d f=1, P=.655 ;$ Fig 1 ).

\section{Time Spent Moving to and Moving Away From the Object}

The Control and Acid groups spent a similar amount of time spent within $5 \mathrm{~cm}$ of the novel object (Control, 11.1\% \pm 9.9\%; Acid, 12.7\% $\pm 6.4 \% ; \mathrm{H}=2.64$, $d f=1, P=.104$; Fig 2A). The proportion of time spent moving away from the novel object $(>10 \mathrm{~cm})$ was significantly different between the Acid $(44.1 \% \pm$ 
$17 \%)$ and Control groups (58.4\% $\pm 25 \% ; \mathrm{H}=4.86 ; d f=1, P=.028 ;$ Fig $2 \mathrm{~B})$. This pattern was similar for the first presentation time, but there were no significant differences between the Acid and Control groups at presentation times 2, 4, and 5 (Table 1). At presentation time 3, the Control group spent less time within $5 \mathrm{~cm}$ than the Acid group, but the reverse was true for time spent at more than $10 \mathrm{~cm}$ (Table 1).

Table 1. Statistical Comparison of Time Spent Within Close Proximity to the Test Object $(<5 \mathrm{~cm})$ and Time Spent Moving Away From Object (>10 cm) for Control (C) and Acid (A) Groups in Each Test Group

\begin{tabular}{|c|c|c|c|c|c|c|c|c|c|c|c|}
\hline \multirow[b]{3}{*}{ Test Group } & \multirow[b]{3}{*}{ Distance (cm) } & \multicolumn{10}{|c|}{ Presentation Time } \\
\hline & & \multicolumn{2}{|c|}{1} & \multicolumn{2}{|c|}{2} & \multicolumn{2}{|c|}{3} & \multicolumn{2}{|c|}{4} & \multicolumn{2}{|c|}{5} \\
\hline & & $C$ & $A$ & C & $A$ & C & $A$ & C & $A$ & C & $A$ \\
\hline 1, Novel & $\begin{array}{l}<5 \\
>10\end{array}$ & $\begin{array}{c}0 \\
90.0\end{array}$ & $\begin{array}{c}21.0 \\
0\end{array}$ & $\begin{array}{c}0 \\
88.3\end{array}$ & $\begin{array}{c}27.0 \\
0\end{array}$ & $\begin{array}{c}0 \\
86.7\end{array}$ & $\begin{array}{c}36.0 \\
1.7\end{array}$ & $\begin{array}{c}1.7 \\
81.6\end{array}$ & $\begin{array}{l}21.7 \\
21.6\end{array}$ & $\begin{array}{c}0 \\
90.0\end{array}$ & $\begin{array}{l}26.7 \\
25.6\end{array}$ \\
\hline 2, Familiar & $\begin{array}{l}<5 \\
>10\end{array}$ & $\begin{array}{l}13.3 \\
32.5\end{array}$ & $\begin{array}{l}46.0 \\
13.7\end{array}$ & $\begin{array}{l}26.7 \\
23.3\end{array}$ & $\begin{array}{l}26.7 \\
20.0\end{array}$ & $\begin{array}{l}18.3 \\
30.0\end{array}$ & $\begin{array}{l}25.0 \\
45.3\end{array}$ & $\begin{array}{l}37.5 \\
21.5\end{array}$ & $\begin{array}{l}41.0 \\
13.3\end{array}$ & $\begin{array}{l}43.3 \\
26.7\end{array}$ & $\begin{array}{l}38.3 \\
15.0\end{array}$ \\
\hline 3, Morphine & $\begin{array}{l}<5 \\
>10\end{array}$ & $\begin{array}{l}16.7 \\
31.7\end{array}$ & $\begin{array}{l}15.0 \\
21.7\end{array}$ & $\begin{array}{c}6.7 \\
43.3\end{array}$ & $\begin{array}{l}13.3 \\
50.0\end{array}$ & $\begin{array}{l}3.3 \\
80\end{array}$ & $\begin{array}{c}11.7 \\
35\end{array}$ & $\begin{array}{c}5.0 \\
83.3\end{array}$ & $\begin{array}{c}6.7 \\
43.3\end{array}$ & $\begin{array}{l}12.0 \\
58.0\end{array}$ & $\begin{array}{l}12.0 \\
55.0\end{array}$ \\
\hline
\end{tabular}

\section{OBR}

There was a significant difference between the OBR on Day 1 (median, 52.0 beats $/ \mathrm{min}$ ) and the OBR on Day 2 before (median, 62.0 beats/min) and after (median, 70.2 beats/min) the presentation of the novel object in the Control group $(H=12.57, d f=2, P=.002)$ and in the Acid group (Day 1 median, 52.0 beats/min; Day 2 before: median, 62.4 beats/min; Day 2 after: 68.8 beats $/ \mathrm{min} ; \mathrm{H}=12.0, d f=2, P=.002$ ). OBR increased significantly after novel object presentation in the Control group (pre-object median, 62 beats/min; post-object median, 68 beats/ min; $W=464, P<.001, n=25$; Fig 3B) and the Acid group (before: median, 60 beats $/ \mathrm{min}$; after: median, 68 beats $/ \mathrm{min}$; $\mathrm{W}=468, P=.001, \mathrm{n}=25$; Fig 3B). Unlike the novel object and familiar object treatment groups, OBR was not different in the Acid group (median, 62 beats $/ \mathrm{min}$ ) compared with the Control group (median, 62 beats $/ \mathrm{min} ; \mathrm{H}=0.01, d f=1, P=.934$ ) on Day 2.

\section{Performance of Nociceptive-Related Behaviors}

The frequency of rocking did not decline with presentation time both before $(\mathrm{H}=8.35, d f=4, P=.080)$ and after the novel object $(H=0.0, d f=4, P=1.0)$. Statistics could not be performed to compare the frequency of rocking before and after presentation of the object, because the data were too low for statistical testing (Fig 4A).

The frequency of rocking declined with time and so there was a difference between presentation times, but this was only significant before the novel object presentation (before: $\mathrm{H}=15.4, d f=4, P=.004$; after: $\mathrm{H}=4.0, d f=4, P=.406)$. There was a reduction in rubbing after novel object presentation, but this was not significant $(\mathrm{W}=690, P=.074 ; \mathrm{n}=15$; Fig 4B).

\section{Comparisons Between Test Groups}

The latency to approach the object was similar for all 3 Acid groups when comparing the 3 test groups to each other $(H=1.25, d f=2, P=.535)$. However, there was a significant difference between the Control 
groups, with Test Group 1 (TG1) having the longest latency to approach (TG1 median, 5.3 min; TG2 median, $1.3 \mathrm{~min}$; TG3 median, $1.5 \mathrm{~min} ; \mathrm{H}=30.1, d f=2, P=.001$ ).

The time spent within $5 \mathrm{~cm}$ of the object was different for both Control (TG1 median, 0\%; TG2 median, 2.7\%; TG3 median, 8.3\%; $\mathrm{H}=44.2, d f=2, P<.001$ ) and Acid groups (TG1 median, 26.7\%; TG2 median, 31.7\%; TG3 median, 11.7\%; $\mathrm{H}=27.8, d f=2, P<.001$ ) when comparing between the 3 test groups. In the Control groups, a greater proportion of time was spent at greater than $10 \mathrm{~cm}$ from the object in Test Groups 1 and 3 (TG1, 88.3\%; TG2, 26.7\%; TG3, 61.1\%; $\mathrm{H}=32.4, d f=2, P<.001$ ), demonstrating the effects of presenting a familiar object. In the Acid group, the Test Group 3 fish spent a much greater proportion of time more than $10 \mathrm{~cm}$ from the object than in the other 2 test groups, suggesting a neophobic response when morphine is administered (TG1, 6.7\%; TG2, 21.5\%; TG3, 45.8\%; $\mathrm{H}=21.1$, $d f=2, P<.001)$.

OBR was similar in all 3 Control groups (TG1, 67 beats/min; TG2, 61 beats/min; TG3, 62 beats/min; $H$ = 4.7, $d f=2, P=.097)$. However, OBR was much higher in the Acid groups of Test Groups 1 and 2 than in Test Group 3 in which morphine was administered (TG1 median, 78 beats/min; TG2 median, 76 beats/min; TG3 median, 62 beats $/ \mathrm{min} ; \mathrm{H}=8.18, d f=2, P=.017$ ).

The frequency of rocking was much higher in Test Group 2 with a familiar object present than in Test Group 1 in which a novel object was presented. The fish of Test Group 3 performed virtually no rocking, demonstrating the antinociceptive effects of morphine (TG1, 0.2 rocks $/ \mathrm{min} ; \mathrm{TG} 2,0.4 \mathrm{rocks} / \mathrm{min} ; \mathrm{TG} 3,0$ rocks/min; $\mathrm{H}=10.6, d f=2, P=.005)$. A similar pattern was shown by the performance of rubbing between the 3 different test groups, with relatively little rubbing being performed when morphine was administered (TG1, $0.3 \mathrm{rubs} / \mathrm{min}$; TG2, $0.6 \mathrm{rubs} / \mathrm{min}$; TG3, $0.1 \mathrm{rubs} / \mathrm{min} ; \mathrm{H}=10.6, d f=2, P=.005$ ).

\section{Discussion}

The control animals in Test Group 1 displayed a classic neophobia to a novel object because they took a relatively long time to approach the object, they spent very little time in close proximity, and the majority of their time was spent moving away from the novel object. These responses are characteristic of neophobia in other animals (eg, rats, ${ }^{52}$ mice ${ }^{20}$, cats ${ }^{50}$ and horse ${ }^{75}$ ). In contrast, the noxiously stimulated animals in Test Group 1 approached the novel object more quickly and spent a large proportion of time near the novel object and less than $20 \%$ of their time moving away from the object. These results would suggest that the nociception the fish were experiencing might have taken up the majority of their attention, and they either ignored the novel object or could not divert attention to a fear response. Therefore, it appears as if attention to the noxious event in these fish was more important than performance of fear behavior in this experimental paradigm. Although the animals experiencing noxious stimulation did not show fearrelated avoidance behavior, they did show reduced nociception-related behaviors, rocking and rubbing, compared with the frequency of these behaviors before presenting the object. This would suggest a complex relationship between the possible nociception experienced and fear motivation. Most of the animals' responses were dominated by the noxious state, and so the fish did not show an appropriate fear response. The reduction in nociception-related behaviors would indicate hypoalgesia. Hypoalgesia has been demonstrated in other animal models of pain ${ }^{22,23,37-39,73}$ and humans ${ }^{47}$ when confronted with a stressful stimulation. This slight hypoalgesia is of interest because it suggests that the degree of fear introduced by the neophobic stimulus did allow the animal to partially divide its attention between fear and nociception.

This behavioral inhibition might have detrimental consequences because an individual experiencing nociception might not respond in an appropriate manner to a fearful situation and this might carry severe penalties. For this particular study species, exposure to a predator could be fatal if the fish react in a 
similar manner to how they responded to a novel object. Other animal studies have shown that exposure to novelty and predators can evoke a stress analgesia with a total reduction in pain reactivity. ${ }^{23,32,36,37,45,53,59,61,65,66,75}$ It has been suggested that the nociception experienced in these studies was possibly not severe and so attention could be diverted away to the concurrent task. ${ }^{23}$ In this study, it is unlikely that the fish would have experienced this type of noxious event before, and so this would be the most severe or intense noxious experience that they would have potentially endured, and the novel object did not resemble a predator and is likely to be less alarming. An alternative hypothesis is that because of the relatively simpler brain structure of fish it might be that they have limited capacity for responding to more than 1 task, unlike higher vertebrates that have highly evolved brains and can partition attention to various tasks at one time. This might be an evolutionary difference between fish and the higher vertebrate groups; however, this remains to be tested.

The behavioral responses by both the Acid and Control groups to a familiar object confirmed that the responses by the control animals in Test Group 1 were neophobia because they approached the object more quickly and spent a larger proportion of time in close proximity and a smaller amount of time moving away from the object. The Acid group also performed more pain-related behaviors in the presence of the familiar object. Fish, therefore, like many other animals, have this capability to discriminate between novel and familiar objects and to show reduced behavioral and physiologic reactions to a familiar object. ${ }^{7,32,53}$ The control fish in Test Group 1 responded physiologically by increasing their ventilation or OBR after the novel object was placed in their tank. This OBR response was not observed in the acid-injected animals in Test Group 1 or in Acid and Control groups in the familiar object tests. Therefore, this increase in OBR might be an indicator of a fear response, and it is well known that fish show a fight or flight stress response similar to that of mammals, ${ }^{55}$ and this includes an increase in breathing rate. In the novel object test in which the fish's attention is dominated by the noxious stimulation, it might be that the OBR does not increase after object presentation because little attention and neural processing can be diverted to this physiologic response. An alternative explanation is that these fish are already at a maximum respiration rate and so show no increase after the novel object.

Intramuscular injection of morphine had a significant analgesic effect in the acid-injected fish by substantially reducing nociception-related behaviors and respiration rate, as well as returning the fear responses to a novel object to normal. The analgesic effects of morphine are well-known in animals and humans; $;^{17,39,53}$ however, virtually no work has been done on analgesia in fish. Fish can become tolerant of morphine and have opioid receptors, ${ }^{34}$ and morphine does impair electric shock aversion training in goldfish. ${ }^{19}$ Morphine has been demonstrated to reduce fear responses, ${ }^{8,9,26,60}$ and there was a slight difference in the neophobia shown by Test Group 3 animals compared with the control animals of Test Group 1. Animals in Test Group 3 approached the novel object as quickly as those that approached a familiar object, and they also spent less time moving away from the object. Therefore, morphine affects fear responses in the trout in a similar way to other animals and humans. ${ }^{9,10,26,60}$

Opioids act as an analgesic by inhibiting the release of substance $P$ and calcitonin gene-related peptide from the terminals of primary afferent nociceptors. ${ }^{51,77}$ In peripheral nerves, opioid action is possibly mediated by local opioid receptors located on primary afferent neurons. ${ }^{77}$ In humans, opioids appear to reduce the distressing, affective component of a noxious, painful event. ${ }^{14}$ Opioids diminish the impact of stress by attenuating an array of physiologic responses including emotional affective states. In this study, morphine ameliorated the behavioral responses to the noxious injection as well as causing a respiratory depression and reducing fear responses. These direct effects of opioids have also been seen in humans and mammals administered with morphine. ${ }^{14,24,77}$ Studies examining opioid receptors in fish have shown that $\mu$ and $\mathrm{k}$ opiate receptors are distributed throughout the fish brain, ie, the telencephalon, optic tectum, cerebellum, and thalamus. ${ }^{16}$ Comparative genetic studies have shown that the opioid receptor family has 
been highly conserved during evolution, with fish opioid receptors having $91 \%$ similarity with human opioid receptors. ${ }^{46}$ Relatively little is known about the effects of endogenous opioids in fish, although enkephalins and $\beta$-endorphins are present in fish neurons. ${ }^{14}$ One of the functions of opioid receptors in mammals is to suppress pain, and it appears they might fulfill the same role here in a lower vertebrate. ${ }^{12}$ A further test that could have been used in this study is to examine the reversal effects of naloxone; however, it has been clearly demonstrated that naloxone blocks the effects of morphine administration in fish. ${ }^{12,19}$ Therefore, there appears to be a complex opioid system in fish affecting nociception, behavior, and physiology.

In this study nociception-related behavior affected fear responses, and one interpretation is that this noxious treatment might command the majority of the attention capacity in fish subject to this experimental situation. In human clinical studies, pain interferes with concurrent, competing tasks, such as learning and memory tests, ${ }^{25,40,62,66,72}$ and some research has shown that attentional strategy as an analgesic has varying success. ${ }^{18,41}$ Clinical studies have demonstrated that emotional states of patients do have an effect on chronic pain. ${ }^{27,66}$ It might be that in intense pain there is a behavioral impairment because little attention can be diverted away from pain processing, whereas in less intense painful situations attention might be easily focused elsewhere. In humans the induction of fear does not affect attention bias toward pain-related information, and this has been confirmed by a number of recent studies. ${ }^{40,62}$ In humans, acute pain can be reduced by avoidance or attention distraction strategies such as hypnosis or engaging in other activities, ${ }^{72,74}$ but these have limited application in severe pain cases (eg, burn wound care $^{32}$ ). Future studies should assess how nociception in fish affects responses to other fearful events, such as the presence of a predator, to determine whether nociception always has such a profound effect.

The present study has shown that the trout's response to noxious stimulation is complicated in nature. This suggests the potential for pain perception in this lower vertebrate. A recent review proposed that fish were incapable of experiencing pain because they lack a neocortex. ${ }^{63}$ This definition of pain means that only human and primates are capable of pain perception, with other mammals, birds, and amphibians also incapable of experiencing pain. Yet many studies have demonstrated pain in monkeys, rats, and mice and in particular birds ${ }^{21}$ that have a very dissimilar brain structure compared with humans. The majority of animal pain researchers omit emotion when defining pain because emotion cannot be measured directly in any animal. ${ }^{4,10,11,49}$ The criteria that have been adopted by many studies examining animal pain are (1) to show the animal has the neural apparatus to detect noxious stimuli that humans have, (2) to demonstrate a noxious event has adverse behavioral and physiologic effects, (3) the animal should learn to avoid this noxious stimulus, and (4) the behavioral impairments during a noxious event should not be simple reflexes. Recent research on the rainbow trout has shown the presence of nociceptors on the head of the trout that are almost identical to human nociceptors in terms of anatomy and electrophysiologic properties. ${ }^{68,70}$ It has also been demonstrated that the trout has a prolonged negative behavioral and physiologic response to a noxious event, and this was also seen in the present study. ${ }^{71}$ Other fish species can learn to avoid noxious stimuli such as electric shock. ${ }^{19}$ The administration of an analgesic reduces these responses to almost normal. Together with the results of this study, the criteria for animal pain have been fulfilled for the trout.

\section{Acknowledgment}

We are grateful to Anthea Springbett (Biometrics) for her advice regarding the statistics. 


\section{References}

1. Amit Z, Galina ZH: Stress-induced analgesia: Adaptive pain suppression. Physiol Rev 66:10911120, 1986

2. Asmundson GJG: Commentary: anxiety sensitivity and the pain experience. Eur J Pain 5:23-25, 2001

3. Barnett SA: Rats. Sci Am 216:78-85, 1967

4. Bateson P: Assessment of pain in animals. Anim Behav 42:827-839, 1992

5. Beattie VE, O'Connell NE, Kilpatrick DJ, Moss BW: Influence of environmental enrichment on welfare-related behavioural and physiological parameters in growing pigs. Anim Sci 70:443-450, 2000

6. Belzung C, LePape G: Comparison of different behavioural test situations used in psychopharmacology for measurement of anxiety. Physiol Behav 56:623-628, 1994

7. Besheer J, Bevins RA: The role of environmental familiarization in novel-object preference. Behav Proc 50:19-29, 2000

8. Blanchard RJ, Kelley MJ, Blanchard DC: Defensive reactions and exploratory behavior in rats. J Comp Physiol Psychol 87:1129-1133, 1974

9. Blanchard DC, Weatherspoon A, Shepherd J, Rodgers RJ, Weiss SM, Blanchard RJ: "Paradoxical" effects of morphine on antipredator defense reactions in wild and laboratory rats. Pharmacol Biochem Behav 40:819-828, 1991

10. Bradshaw EL, Bateson P: Welfare implications of culling red deer (Cervus elaphus). Anim Welfare 9:3-24, 2000

11. Broom DM: Animal welfare: concepts and measurements. J Anim Sci 69:4167-4175, 1991

12. Darlison MG, Greten FR, Harvey RJ, Kreienkamp HJ, Stühmer T, Zwiers H, Lederis K, Richter D: Opioid receptors from a lower vertebrate (Catostomus commersoni): Sequence, pharmacology, coupling to a G-protein-gated inward-rectifying potassium channel (GIRK1) and evolution. Proc Natl Acad Sci U S A 94:8214-8219, 1997

13. Davis M: Conditioned fear-induced opiate analgesia: A competing motivational state theory of stress-induced analgesia. Ann N Y Acad Sci 467:40-54, 1979

14. Drolet G, Dumont EC, Gosselin I, Kinkead R, Laforest S, Trottier JF: Role of endogenous opioid system in the regulation of the stress response. Prog Neuropsychopharmacol Biol Psychiatry 25:729-741, 2001

15. Dufton BD: Cognitive failure and chronic pain. Int J Psychiatry Med 19:291-297, 1989

16. Ebbesson LOE, Deviche P, Ebbesson SOE: Distribution and changes in mu- and kappa-opiate receptors during the midlife neurodevelopmental period of Coho salmon, Oncorhynchus kisutch. J Comp Neurol 366:448-464, 1996

17. Ebersberger A, Anton F, Tolle TR, Zieglgansberger W: Morphine 5-HT2 and 5-HT3 receptor antagonists reduce Cfos expression in the trigeminal nuclear-complex following noxious chemical-stimulation of the rat nasal-mucosa. Brain Res 676:336-342, 1995

18. Eccleston C: Chronic pain and distraction: An experimental investigation into the role of sustained and shifting attention in the processing of chronic persistent pain. Behav Res Ther 33:391-405, 1995

19. Ehrensing RH, Michell GF, Kastin AJ: Similar antagonism of morphine analgesia by MIF-1 and naxolone in Carassius auratus. Pharm Biochem Behav 17:757-761, 1982

20. File SE: Factors controlling measures of anxiety and responses to novelty in the mouse. Behav Brain Res 125:151-157, 2001

21. Gentle MJ: Pain in birds. Anim Welfare 1:235-247, 1992

22. Gentle MJ: Attentional shifts alter pain perception in the chicken. Anim Welfare 10:S187-194, 2001

23. Gentle MJ, Tilston VL: Reduction in peripheral inflammation by changes in attention. Physiol Behav 66:289-292, 1999

24. Good AJ, Westbrook RF: Effects of a microinjection of morphine into the amygdala on the acquisition and expression of conditioned fear and hypoalgesia in rats. Behav Neurosci 109:631641,1995

25. Grace G, Nielson W, Hopkins M, Berg M: Concentration and memory deficits in patients with fibromyalgia syndrome. J Clin Exp Neuropsychol 21:477-487, 1999 
26. Griebel G, Belzung C, Misslin R, Vogel E: The free-exploratory paradigm: An effective method for measuring neophobic behaviour in mice and testing potential neophobia-reducing drugs. Behav Pharmacol 4:637-644, 1993

27. Haythornthwaite JA, Benrud-Larson LM: Psychological aspects of neuropathic pain. Clin J Pain 16:S101-105, 2000

28. Hall FS, Humby T, Wilkinson LS, Robbins TW: The effects of isolation-rearing on preference by rats for a novel environment. Physiol Behav 62:299-303, 1997

29. Hall FS, Humby T, Wilkinson LS, Robbins TW: The effects of isolation-rearing of rats on behavioural responses to food and environmental novelty. Physiol Behav 62:281-290, 1997

30. Hemsworth PH, Price EO, Borgwardt R: Behavioural responses of domestic pigs and cattle to humans and novel stimuli. Appl Anim Behav Sci 50:43-56, 1996

31. Hendrie CA: The calls of murine predators activate endogenous analgesia mechanisms in laboratory mice. Physiol Behav 49:569-573, 1991

32. Hoffman HG, Doctor JN, Patterson DR, Carrougher GJ, Furness TA III. Virtual reality as an adjunctive pain control during burn wound care in adolescent patients. Pain 85:305-309

33. Jamison RN, Sbrocco T, Paris WCV: The influence of problems with concentration and memory on emotional distress and daily activities in chronic pain patients. Int J Psychiatry Med 18:183191, 1988

34. Jensen GA, Green NM: Morphine metabolism and morphine tolerance in goldfish. Anesthesiology 32:231-235, 1970

35. Kavaliers $\mathrm{M}$ : Brief exposure to a natural predator, the short-tailed weasel, induces benzodiazepine-sensitive analgesia in white-footed mice. Physiol Behav 43:187-193, 1988

36. Kavaliers M: Responsiveness of deer mice to a predator, the short-tailed weasel: Population differences and neuromodulatory mechanisms. Physiol Zool 63:388-407, 1990

37. Kavaliers M, Colwell DD: Sex differences in opioid and non-opioid mediated predator-induced analgesia in mice. Brain Res 568:173-177, 1991

38. Kavaliers M, Colwell DD: Parasite infection attenuates nonopioid mediated predator-induced analgesia in mice. Physiol Behav 55:505-510, 1994

39. Kavaliers M, Innes DGL: Sex differences in the effects of Tyr-MIF-1 on morphine- and stressinduced analgesia. Peptides 13:1295-1297, 1992

40. Keogh E, Cochrane M: Anxiety sensitivity, cognitive biases, and the experience of pain. J Pain 3:320-329, 2002

41. Keogh E, Hatton K, Ellery D: Avoidance versus focused attention and the perception of pain: Differential effects for men and women. Pain 85:225-230, 2000

42. Kewman DG, Vaishampayan N, Zald D, Han B: Cognitive impairments in musculoskeletal pain patients. Int J Psychiatry Med 21:252-262, 1991

43. Kuhajda MC, Thorn BE, Klinger MR, Rubin NJ: The effect of headache pain on attention (encoding) and memory (recognition). Pain 97:213-221, 2002

44. Lester LS, Fanselow MS: Exposure to cat produces opioid analgesia in rats. Behav Neurosci 99:765-769, 1985

45. Lewis JW, Cannon JT, Libeskind JC: Opioid and non-opioid mechanisms of stress analgesia. Science 208:623-625, 1980

46. Li X, Keith DE, Evans CJ: Mu opioid receptor-like sequences are present throughout vertebrate evolution. J Mol Evol 43:179-184, 1996

47. Lobbezoo F, Trulsson M, Jacobs R, Svensson P, Cadden SW, van Steenberghe D: Topical review: Modulation of trigeminal sensory input in humans-Mechanisms and clinical implications. J Orofac Pain 16:9-21, 2002

48. Martinez V, Thakur S, Mogil JS, Tache Y, Mayer EA: Differential effects of chemical and mechanical colonic irritation on behavioural pain response to intraperitoneal acetic acid in mice. Pain 81:179-186, 1999

49. Mason GJ, Cooper J, Clarebrough C: Frustrations of fur-farmed mink: Mink may thrive in captivity but they miss having water to romp about in. Nature 410:35-36, 2001

50. McCune S: The impact of paternity and early socialization on the development of cats' behaviour to people and novel objects. Appl Anim Behav Sci 45:109-124, 1995 51. McNally GP: Pain facilitation circuits in the mammalian central nervous system: Their behavioural significance and role in morphine analgesic tolerance. Neurosci Biobehav Rev 23:1059-1078, 1999 
51. McNally GP, Akil H: Effects of contextual withdrawal or olfactory cues previously paired with morphine withdrawal on behavior and pain sensitivity in the rat. Psychopharmacology 156:381387, 2001

52. Miczek KA, Thomson ML, Shuster L: Opioid-like analgesia in defeated mice. Science 215:15201522, 1982

53. Nott HMR, Sibly RM: Responses to novel food by rats: The effect of social rank. Crop Protection 12:89-94, 1993

54. Overli O, Pottinger TG, Carrick TR, Overli E, Winberg S: Differences in behaviour between rainbow trout selected for high- and low-stress responsiveness. J Exp Biol 205:391-395, 2002

55. Petrovic P, Petersson KM, Ghatan PH, Stone-Elander S, Ingvar M: Pain-related cerebral activation is altered by a distracting cognitive task. Pain 85:19-30, 2000

56. Platt DM, Novak MA: Perception of novel changes in a familiar environment by socially-housed rhesus monkeys. Am J Primatol 47:117-131, 1999

57. Plomb GJJ, Maes RAA, van Ree JM: Disposition of morphine in rat brain: Relationship to biological activity. J Pharmacol Exp Ther 217:181-188, 1980

58. Rodgers RJ, Randall JI. Defensive analgesia in rats and mice. Psychol Rev 37:335-347, 1987

59. Rodgers RJ, Shepherd JK: Prevention of the analgesic consequences of social defeat in male mice by 5-HT1A anxiolytics, buspirone, gepirone and ipsapirone. Psychopharmacology 99:374380, 1989

60. Rodgers RJ, Shepherd JK: Stereospecific inhibition of non-opioid defeat analgesia in male mice by MDL 728332, a selective 5-HT1A receptor agonist. Eur J Pharmacol 182:581-585, 1990

61. Roelofs J, Peters ML, Vlaeyen JWS: Selective attention for pain-related information in healthy individuals: The role of pain and fear. Eur J Pain 6:331-339, 2002

62. Rose JD: The neurobehavioral nature of fishes and the question of awareness and pain. Fisheries Sci 10:1-38, 2002

63. Russell PA: Relationships between exploratory behavior and fear: A review. Br J Psychol 64:417433, 1973

64. Schanberg LE, Sandstrom MJ, Starr K, Gil KM, Lefebvre JC, Keefe FJ, Affleck G, Tennen H: The relationship of daily mood and stressful events to symptoms in juvenile rheumatic disease. Arthritis Care Res 13:33-41, 2000

65. Schnurr RF, MacDonald MR: Memory complaints in chronic pain. Clin J Pain 11:103-111, 1995

66. Seferta A, Guay PJ, Marzinotto E, Lefebvre L: Learning differences between feral pigeons and Zenaida doves: The role of neophobia and human proximity. Ethol 107:281-293, 2001

67. Sneddon LU: Anatomical and electrophysiological analysis off the trigeminal nerve in the rainbow trout Onchorynchus mykiss. Neurosci Lett 312:167-171, 2002

68. Sneddon LU, Gentle MJ: Receptor types on the head of the rainbow trout: Are nociceptors present? Comp Biochem Physiol 32A(Suppl 1):S42, 2002

69. Sneddon LU, Braithwaite VA, Gentle MJ: Trigeminal somatosensory innervation of the head of the rainbow trout with particular reference to nociception. Brain Res 972:44-52, 2003

70. Sneddon LU, Braithwaite VA, Gentle MJ. Do fish have nociceptors: Evidence for the evolution of a vertebrate sensory system. Proc R Soc Lond B 270:1115-1121

71. Tan S: Cognitive and cognitive-behavioral methods for pain control: A selective review. Pain 12:201-228, 1982

72. Teskey GC, Kavaliers M: Effects of opiate agonists and antagonists on aggressive encounters and subsequent opioid-induced analgesia, activity and feeding responses. Pharmacol Biochem Behav 31:43-52, 1988

73. Villemure $C$, Bushnell MC: Cognitive modulation of pain: How do attention and emotion influence pain processing? Pain 95:195-199, 2002

74. Visser EK, van Reenen CG, Hopster H, Schilder MBH, Knaap JH, Barneveld A, Blokhuis HJ: Quantifying aspects of young horses' temperament: Consistency of behavioural variables. Appl Anim Behav Sci 74:241-258, 2001

75. Visser EK, van Reenen CG, van der Werf JTN, Schilder MBH, Knapp JH, Barneveld A, Blokhuis $\mathrm{HJ}$ : Heart rate and heart rate variability during a novel object test and a handling test in young horses. Physiol Behav 76:289-296, 2002

76. Wheeler M, Oderda GM, Ashburn MA, Lipman AG: Adverse events associated with postoperative opioid analgesia: A systematic review. J Pain 3:159-180, 2002 
77. Wisenden BD, Harter KR: Motion, not shape, facilitates association of predation risk with novel objects by fathead minnows (Pimephales promelas). Ethol 107:357-364, 2001 